\title{
HUBUNGAN PENGUASAAN KONSEP DAN SIKAP ILMIAH PESERTA DIDIK DALAM PEMBELAJARAN BERBASIS LABORATORIUM VIRTUAL DI MASA PANDEMI COVID-19
}

\author{
Indri Pratiwi*, Sardianto Markos Siahaan, Syuhendri Syuhendri
}

Program Studi Magister Pendidikan Fisika FKIP Universitas Sriwijaya

Jalan Srijaya Negara Bukit Besar Palembang

e-mail : indri.heryadi@gmail.com

\begin{tabular}{c|c|c}
\hline Diterima 16 November 2021 & Disetujui 11 Desember 2021 & Dipublikasikan 31 Desember 2021 \\
\hline \multicolumn{3}{l}{ https://doi.org/10.33369/jkf.4.3.177-184 } \\
\hline
\end{tabular}

\begin{abstract}
ABSTRAK
Penelitian ini bertujuan untuk mengetahui hubungan penguasaan konsep dan sikap ilmiah peserta didik dalam pembelajaran berbasis laboratorium virtual pada materi Dinamika Gerak. Metode penelitian yang digunakan adalah pre experimental dengan desain one-group pretest-posttest. Penelitian dilaksanakan pada semester genap tahun ajaran 2020/2021 di salah satu Madrasah Aliyah (MA) kota Prabumulih. Populasi penelitian ini adalah seluruh kelas X IPA, yakni sebanyak tiga kelas, dengan satu kelas sampel yang diambil dengan teknik purposive sampling. Data kuantitatif penguasaan konsep diperoleh melalui pemberian tes secara online dengan bentuk pilihan ganda. Tes diberikan sebanyak dua kali, yakni pre-test dan post-test. Data kuantitatif sikap ilmiah didapat melalui lembar observasi yang diamati selama kegiatan pembelajaran berlangsung. Berdasarkan hasil penelitian diperoleh informasi bahwa terdapat hubungan penguasaan konsep dan sikap ilmiah peserta didik dalam pembelajaran berbasis laboratorium virtual pada materi Dinamika Gerak dengan tingkat korelasi sedang. Jadi, penguasaan konsep Fisika yang baik dapat diperoleh dari sikap ilmiah yang baik pula. Maka pembelajaran dengan laboratorium virtual dapat dijadikan alternatif pemilihan media pembelajaran dalam melatihkan sikap ilmiah peserta didik dan mempermudah peserta didik dalam menguasai konsep Fisika.
\end{abstract}

Kata kunci: Laboratorium virtual, penguasaan konsep, sikap ilmiah, Dinamika Gerak

\begin{abstract}
This study aims to determine the relationship between mastery of concepts and scientific attitudes of students in virtual laboratory-based learning on Motion Dynamics material. The research method used is pre-experimental with a onegroup pretest-posttest design. The research was carried out in the even semester of the 2020/2021 academic year in one of the Madrasah Aliyah (MA) in Prabumulih. The population of this research is all class X IPA, which is three classes, with one class sample taken by purposive sampling technique. Quantitative data for mastery of concepts was obtained through giving online tests in the form of multiple choice. The test was given twice, namely pre-test and post-test. Quantitative data on scientific attitudes were obtained through observation sheets that were observed during the learning activities. Based on the results of the study, information was obtained that there was a relationship between mastery of concepts and scientific attitudes of students in virtual laboratory-based learning on the material of Motion Dynamics with a moderate level of correlation. So, a good mastery of Physics concepts can be obtained from a good scientific attitude as well. So learning with a virtual laboratory can be used as an alternative for selecting learning media in training students' scientific attitudes and making it easier for students to master the concepts of Physics.
\end{abstract}

Keywords: Virtual laboratory, mastery of concepts, scientific attitude, Dynamics of Motion

\section{PENDAHULUAN}

Sikap adalah sifat umum yang mendukung penilaian dan perasaan emosional seseorang berdasarkan apa yang dilihat, didengar, dipikirkan, dan dilakukan oleh setiap individu (1). Proses pembelajaran dan penilaian sikap peserta didik di sekolah/madrasah kurang mendapat perhatian guru. Padahal sikap berperan penting dalam menentukan kualitas peserta didik. Maka guru perlu menumbuhkembangkan sikap positif ke dalam diri peserta didik. 
Dimensi sikap yang perlu dikembangkan dalam pembelajaran yaitu sikap terhadap sains dan sikap ilmiah (2). Sikap terhadap sains mengacu pada respon peserta didik setelah mereka mempelajari sains. Peserta didik yang melek sains akan memiliki sikap positif terhadap sains, peduli terhadap lingkungan, dan akan menjalani gaya hidup berkelanjutan yang berwawasan lingkungan dengan mengapresiasi pendekatan saintifik inkuiri. Sedangkan sikap ilmiah berkaitan dengan disposisi seseorang terhadap penelitian atau aktivitas ilmiah, juga mengacu pada sikap yang diperlukan dalam upaya mengeksplorasi atau memahami fenomena alam.

Selain sikap, permasalahan mendasar yang sudah lama dihadapi dalam pendidikan sains di Indonesia yakni masih rendahnya penguasaan konsep sains (3). Padahal konsep merupakan bagian dasar yang harus dipahami oleh peserta didik di dalam pembelajaran (4). Seseorang dikatakan menguasai konsep materi jika orang tersebut mengerti dengan baik konsep materi yang dipelajarinya sehingga mampu menjelaskan kembali dengan versinya sendiri sesuai dengan pengetahuan yang dimilikinya (5). Maka peserta didik perlu diarahkan untuk mempelajari konsep materi secara mendalam di dalam proses pembelajaran.

Salah satu mata pelajaran yang dipelajari di Sekolah Menengah Atas/Madrasah Aliyah adalah Fisika. Fisika mempelajari keadaan dan kejadian alam yang tak hidup beserta semua interaksi yang menyertainya melalui serangkaian metode ilmiah sehingga diperoleh fakta, konsep, prinsip, hukum, dan teori yang dibangun atas dasar sikap ilmiah. Maka pembelajaran Fisika di sekolah/madrasah seharusnya dilaksanakan secara berdampingan dengan kegiatan eksperimen atau praktikum yang dibangun dengan sikap ilmiah. Tujuannya yaitu agar dapat melatihkan peserta didik pada kegiatan metode ilmiah dan dapat mendorong peserta didik untuk aktif di dalam proses pembelajaran.

Merujuk pada penjelasan di atas maka sikap ilmiah diperlukan dalam proses pembelajaran Fisika. Menumbuhkan sikap ilmiah yang positif kepada peserta didik perlu dilakukan guna mendukung keaktifan peserta didik dalam proses pembelajaran. Tanpa sikap ilmiah yang positif maka peserta didik cenderung hanya menjadi pengingat konsep ilmiah, sementara sikap ilmiah merupakan aspek penting sebagai fokus selama percobaan (6).

Telah disebutkan juga bahwa pembelajaran Fisika seharusnya dilaksanakan secara berdampingan dengan kegiatan eksperimen atau praktikum. Tujuannya adalah agar dapat melatihkan peserta didik pada kegiatan metode ilmiah serta dapat mendorong peserta didik terlibat aktif di dalam proses pembelajaran. Adanya kegiatan praktikum juga dapat mendukung pembelajaran yang bermakna dengan menghubungkan antara informasi baru dengan informasi yang sudah ada (7). Dengan demikian guru dalam melaksanakan proses pembelajaran sains tidak hanya berfokus pada pemberian materi yang berupa fakta, konsep, hukum, dan teori, melainkan juga memfasilitasi proses ilmiah peserta didik (8).

Hasil observasi pada Madrasah Aliyah yang diteliti bahwa madrasah tersebut sudah dilengkapi dengan fasilitas ruang laboratorium Fisika untuk melakukan praktikum. Alat dan bahan praktikum Fisika yang tersedia di laboratorium juga sudah cukup banyak. Namun alat dan bahan praktikum yang tersedia tidak dapat digunakan untuk menunjang semua kegiatan praktikum Fisika di SMA/MA.

Keterbatasan alat dan bahan untuk melakukan praktikum di era digital saat ini dapat diminimalisir dengan hadirnya peralatan teknologi. Aplikasi internet, CD-ROM, teknologi video dan berbagai peralatan pendukung komputer, serta program software adalah beberapa contoh penggunaan TIK yang diterapkan di dalam proses pembelajaran (9).

Hadirnya teknologi dapat dijadikan solusi dalam membantu memberikan penekanan materi/konsep pembelajaran, karena pembelajaran yang hanya menyampaikan materi/konsep saja tidak mengarah pada pembelajaran yang efektif, sedangkan pembelajaran saat ini diarahkan untuk mengembangkan pemahaman dan menerapkan pengetahuan konsep (10). Maka pemanfaatan TIK dalam pembelajaran memberikan dampak positif dalam memudahkan proses pembelajaran di dalam kelas dan membantu peserta didik menguasai konsep materi pembelajaran.

Namun, diperlukan kehati-hatian dalam pemilihan peralatan teknologi. Kehati-hatian dalam pemilihan peralatan teknologi bertujuan agar peralatan teknologi yang dipilih dapat sesuai dengan kebutuhan pembelajaran dan dapat memberikan kontribusi positif kepada guru maupun peserta

Hubungan Penguasaan Konsep dan Sikap IImiah Peserta Didik dalam Pembelajaran Berbasis Laboratorium Virtual di Masa.... Indri Pratiwi, Sardianto Markos Siahaan, Syuhendri 
didik. Karena teknologi yang digunakan secara tepat akan membantu pengguna mencapai tujuan dan memberikan kemudahan dalam mencapai tujuan tersebut (11).

Salah satu teknologi yang pemanfaatannya belum begitu banyak digunakan secara kontinu adalah laboratorium virtual. Laboratorium virtual merupakan teknologi komputer interaktif yang dapat digunakan sebagai alternatif dari laboratorium real, dimana didalamnya memberikan kesempatan kepada peserta didik untuk melakukan eksperimen sehingga peserta didik berperan aktif dalam kegiatan tersebut (12). Dengan begitu, laboratorium virtual dapat dijadikan sebagai salah satu sumber pembelajaran berbasis teknologi yang dapat digunakan dalam menumbuhkan sikap ilmiah peserta didik melalui praktikum virtual. Adanya laboratorium virtual juga diharapkan dapat menjadi alternatif bagi kendala-kendala yang dihadapi di laboratorium real.

Laboratorium virtual yang dapat digunakan dalam pembelajaran salah satunya adalah PhET interactive simulation. PhET interactive simulation dikembangkan oleh tim dari University of Colorado Boulder. PhET interactive simulation berupa simulasi sains dan matematika interaktif yang dapat dioperasikan dengan program java, flash, atau HTML5. Kelebihan simulasi interaktif PhET diantaranya: a. setiap simulasi telah diuji dan dievaluasi secara ekstensif untuk memastikan efektivitas pendidikan; b. dapat digunakan secara online melalui jaringan internet maupun secara offline dengan cara diunduh ke komputer; c. open source (sumber terbuka) dan gratis untuk semua pengguna; d. tampilannya menarik karena mirip permainan; dan e. sarana peserta didik untuk melakukan eksplorasi dan penemuan (13).

Hasil observasi pada Madrasah Aliyah yang diteliti juga menunjukkan bahwa untuk mempermudah proses pembelajaran para guru sudah memanfaatkan media pembelajaran berbasis TIK, seperti menggunakan LCD dalam menayangkan slide presentasi, video, dan lainnya. Namun, dalam hal pelaksanaan kegiatan praktikum yang melibatkan teknologi seperti pemanfaatan laboratorium virtual belum dilaksanakan.

Berdasarkan uraian yang telah diungkapkan maka strategi yang bisa digunakan agar penguasaan konsep dan sikap ilmiah peserta didik dapat meningkat diantaranya dengan memanfaatkan teknologi sebagai media pembelajaran, melaksanakan kegiatan praktikum yang dilandasi sikap ilmiah, dan memilih strategi pembelajaran yang berlandaskan pendekatan ilmiah. Maka dari itu penelitian dengan menggunakan laboratorium virtual dengan pendekatan ilmiah perlu dilakukan, terutama pada materi Dinamika Gerak kelas X. Sebab, Dinamika Gerak merupakan salah satu bahasan materi yang banyak mendukung kegiatan praktikum sehingga dapat membantu peserta didik dalam menumbuhkan sikap ilmiah dan menampilkan banyak pengetahuan konsep. Lebih jauh, banyak penelitian dari berbagai negara memfokuskan penelitiannya pada Mekanika Newton (salah satunya Dinamika Gerak) karena hasil penelitian mengungkapkan bahwa pada materi ini pemahaman konseptual peserta didik masih rendah dan juga paling banyak ditemukan kesalahpahaman konsep atau miskonsepsi (14).

Selain itu, laporan hasil Ujian Nasional (UN) Pusat Penilaian Pendidikan Kementerian Pendidikan dan Kebudayaan (15) menyebutkan bahwa perolehan rata-rata nilai Fisika pada materi Dinamika di Madrasah Aliyah yang diteliti untuk tahun ajaran 2016/2017 sebesar 37,14, tahun ajaran 2017/2018 sebesar 30,86, dan tahun ajaran 2018/2019 sebesar 35,24. Berdasarkan data tersebut terlihat bahwa perolehan nilai Fisika untuk tiga tahun terakhir pada materi Dinamika masih dikategorikan kurang.

Penelitian terdahulu menyebutkan bahwa pembelajaran berbasis praktikum memiliki pengaruh positif terhadap pengembangan sikap ilmiah peserta didik (16). Peningkatan sikap ilmiah peserta didik menggunakan pembelajaran berbasis praktikum juga menunjukkan hasil yang lebih baik dibandingkan dengan menggunakan pembelajaran konvensional. Penelitian lain juga menemukan bahwa pembelajaran berbasis eksperimen virtual efektif meningkatkan penguasaan konsep Listrik Dinamis mahasiswa pada perkuliahan Fisika Dasar II di Program Studi Pendidikan Fisika Universitas Lampung (17). Lebih lanjut, penelitian lain menyebutkan bahwa pembelajaran dengan simulasi PhET pada materi Rangkaian Listrik di Program Studi Pendidikan Fisika Universitas Almuslim dapat meningkatkan penguasaan konsep mahasiswa dengan kategori sedang dan mendapatkan respon positif dari mahasiswa dengan kategori baik (18). Penelitian-penelitian 
terdahulu tersebut memperkuat untuk dilakukannya penelitian penggunaan laboratorium virtual di dalam proses pembelajaran dengan melihat hubungan antara penguasaan konsep dan sikap ilmiah.

Berdasarkan latar belakang yang telah dikemukakan, maka rumusan masalah pada penelitian ini adalah apakah terdapat hubungan penguasaan konsep dan sikap ilmiah peserta didik dalam pembelajaran berbasis laboratorium virtual pada materi Dinamika Gerak? Sedangkan tujuan penelitian ini adalah untuk mengetahui terdapat hubungan penguasaan konsep dan sikap ilmiah peserta didik dalam pembelajaran berbasis laboratorium virtual pada materi Dinamika Gerak.

\section{METODE PENELITIAN}

Penelitian ini menggunakan metode pre experimental dengan desain one-group pretestposttest. Penelitian dilaksanakan di salah satu Madrasah Aliyah (MA) kota Prabumulih pada semester genap tahun ajaran 2020/2021. Penelitian ini bertepatan di masa pandemi Covid-19 sehingga kegiatan pembelajaran dilaksanakan dengan sistem pembelajaran jarak jauh. Populasi penelitian adalah seluruh kelas X IPA, yakni sebanyak tiga kelas. Sampel penelitian yang digunakan sebanyak satu kelas dengan jumlah 28 peserta didik dan diambil dengan teknik purposive sampling.

Teknik pengumpulan data penguasaan konsep berupa tes secara online. Tes dilakukan sebanyak dua kali, yaitu pre-test dan post-test. Pre-test diberikan sebelum perlakuan pembelajaran dengan laboratorium virtual, dengan tujuan untuk mengetahui keadaan awal peserta didik. Sedangkan post-test diberikan setelah perlakuan pembelajaran dengan laboratorium virtual, tujuannya untuk mengetahui capaian penguasaan konsep Dinamika Gerak peserta didik. Penilaian tes berbentuk pilihan ganda sebanyak 30 butir soal dengan menggunakan instrumen FCI (Force Concept Inventory)).

Sedangkan teknik pengumpulan data sikap ilmiah berupa observasi yang diamati selama kegiatan pembelajaran berlangsung melalui lembar observasi sikap ilmiah dengan menggunakan skala Likert. Hubungan penguasaan konsep dan sikap ilmiah kemudian dianalisis menggunakan uji korelasi. Namun terlebih dahulu dilakukan perhitungan persyaratan analisis data, yaitu uji normalitas dan uji homogenitas. Rumus uji korelasi yang digunakan yaitu:

$$
r_{\text {hitung }}=\frac{n\left(\sum Y_{1} Y_{2}\right)-\left(\sum Y_{1}\right)\left(\sum Y_{2}\right)}{\sqrt{\left\{n \sum Y_{1}^{2}-\left(\sum Y_{1}\right)^{2}\right\}\left\{n \sum Y_{2}^{2}-\left(\sum Y_{2}\right)^{2}\right\}}}
$$

\section{HASIL DAN PEMBAHASAN}

Terdapat dua data yang dianalisis pada penelitian yang dilakukan, yakni data sikap ilmiah dan data penguasaan konsep. Data sikap ilmiah peserta didik diperoleh melalui lembar observasi yang diamati oleh sesama peserta didik (penilaian antar teman) di dalam kelompok percobaan. Masingmasing peserta didik mengamati teman satu kelompoknya dan menuliskan hasil pengamatan mereka dengan memberikan tanda centang pada lembar observasi yang telah dibagikan kepada peserta didik.

Sedangkan data mengenai penguasaan konsep Dinamika Gerak peserta didik diperoleh melalui pemberian tes menggunakan instrumen FCI yang telah diterjemahkan ke dalam bahasa Indonesia. Force Concept Inventory (FCI) merupakan instrumen soal konsep yang dirancang untuk mengkaji pemahaman peserta didik terhadap konsep-konsep dalam mekanika Newton, seperti kinematika, hukum I Newton, hukum II Newton, hukum III Newton, prinsip superposisi, dan jenis-jenis gaya: gaya kontak dan gaya gravitasi (20). FCI yang telah diterjemahkan ke dalam bahasa Indonesia telah berhasil dalam proses validasi dan uji reliabilitas.

Sebelum dilakukan uji hipotesis untuk melihat ada tidaknya hubungan penguasaan konsep dan sikap ilmiah, terlebih dahulu dilakukan uji normalitas dan uji homogenitas data. Uji normalitas dilakukan untuk mengetahui apakah data berdistribusi normal atau tidak, dalam hal ini adalah data pretest dan data posttest. Pengujian normalitas dilakukan dengan statistik uji chi-kuadrat. Hasil uji normalitas disajikan pada tabel berikut. 
Tabel 1. Hasil Uji Normalitas Data dengan Statistik $C h i$-kuadrat

\begin{tabular}{cccc}
\hline Data & $\chi_{\text {hitung }}^{2}$ & $\chi_{\text {tabel }}^{2}$ & Keterangan \\
\hline Pretest & 5.47 & \multirow{2}{*}{11.07} & Terdistribusi \\
Posttest & 9.93 & & normal \\
\hline
\end{tabular}

Cara untuk menentukan data berdistribusi normal atau tidak yaitu dengan membandingkan hasil $\chi_{\text {hitung }}^{2}$ dengan $\chi_{\text {tabel }}^{2}$. Ketentuannya yaitu jika $\chi_{\text {hitung }}^{2}$ lebih kecil atau sama dengan $\chi_{\text {tabel }}^{2}$ maka data tersebut berdistribusi normal, sebaliknya jika $\chi_{\text {hitung }}^{2}$ lebih besar dari $\chi_{\text {tabel }}^{2}$ maka data tersebut tidak berdistribusi normal. Berdasarkan perhitungan uji normalitas diperoleh $\chi_{\text {hitung }}^{2}<\chi_{\text {tabel }}^{2}$ sehingga disimpulkan bahwa untuk data pretest maupun posttest berdistribusi normal.

Setelah dilakukan uji normalitas, tahapan selanjutnya adalah melakukan uji homogenitas data. Uji homogenitas dilakukan untuk mengetahui kesamaan varians antara sampel data pretest dan data posttest. Hasil uji homogenitas diberikan pada tabel berikut.

Tabel 2. Hasil Uji Homogenitas

\begin{tabular}{ccccc}
\hline Sampel Data & Varian $\left(\boldsymbol{s}^{2}\right)$ & $\boldsymbol{F}_{\text {hitung }}$ & $\boldsymbol{F}_{\text {tabel }}$ & Keterangan \\
\hline Pretest & 39.79 & 3.49 & 4.21 & Homogen
\end{tabular}

Menentukan homogen atau tidaknya variansi sampel yaitu dengan membandingkan hasil $F_{\text {hitung }}$ dengan $F_{\text {tabel }}$. Ketentuannya yaitu jika $F_{\text {hitung }}$ lebih kecil atau sama dengan $F_{\text {tabel }}$ maka sampel homogen, sebaliknya jika $F_{\text {hitung }}$ lebih besar dari $F_{\text {tabel }}$ maka sampel tersebut tidak homogen. Berdasarkan perhitungan uji homogenitas diperoleh $F_{\text {hitung }}<F_{\text {tabel }}$ sehingga disimpulkan bahwa sampel tersebut homogen.

Setelah uji normalitas dan uji homogenitas data dilakukan, maka selanjutnya melakukan uji hipotesis. Rumus uji korelasi digunakan dalam pengujian hipotesis. Rumusan hipotesis yang diuji adalah:

Ho: tidak terdapat hubungan penguasaan konsep dan sikap ilmiah peserta didik dalam pembelajaran berbasis laboratorium virtual pada materi Dinamika Gerak

$\mathrm{Ha}$ : terdapat hubungan penguasaan konsep dan sikap ilmiah peserta didik dalam pembelajaran berbasis laboratorium virtual pada materi Dinamika Gerak

Kriteria pengujian hipotesisnya yaitu jika $r_{\text {hitung }} \leq r_{\text {tabel }}$ maka $H o$ diterima, sebaliknya jika $r_{\text {hitung }}$ $>r_{\text {tabel }}$ maka $H o$ ditolak. Hasil uji korelasi untuk penguasaan konsep dan sikap ilmiah diberikan pada tabel di bawah ini.

\begin{tabular}{ccc}
\multicolumn{3}{c}{ Tabel 3. Hasil Uji Korelasi } \\
\hline $\boldsymbol{r}_{\text {hitung }}$ & $\boldsymbol{r}_{\text {tabel }}$ & Keterangan \\
\hline 0.589 & 0.374 & Ha diterima
\end{tabular}

Berdasarkan perhitungan uji korelasi diperoleh $r_{\text {hitung }}>r_{\text {tabel }}$ yang berarti $\mathrm{Ha}$ diterima. Sehingga disimpulkan bahwa terdapat hubungan penguasaan konsep dan sikap ilmiah peserta didik dalam pembelajaran berbasis laboratorium virtual pada materi Dinamika Gerak.

Adanya hubungan penguasaan konsep dan sikap ilmiah peserta didik berdasarkan hasil penelitian yang diungkapkan di atas karena kegiatan praktikum virtual dapat memfasilitasi peserta didik secara aktif untuk melakukan penyelidikan terhadap konsep-konsep materi yang dilandasi dengan sikap ilmiah. Peserta didik dapat mengumpulkan data secara berulang kali dan dapat mengubah setiap variabel yang terkait sesuai kebutuhan adalah salah satu kelebihan dari penggunaan laboratorium virtual. Hasil pengerjaan juga dapat terlihat secara langsung. Dengan demikian peserta didik dapat memperoleh data secara cepat, tepat, dan akurat. Hal ini bersesuaian dengan pernyataan bahwa praktikum virtual memberikan banyak kesempatan kepada peserta didik untuk mengubah variabel dan melihat perubahan secara langsung hasil pengamatan pada aplikasi laboratorium virtual sehingga penerapan penggunaan laboratorium virtual efektif dalam meningkatkan pencapaian konseptual peserta didik (21).

Selanjutnya setelah peserta didik memperoleh data-data praktikum, peserta didik dapat menginterpretasikan data dan membuat kesimpulan dengan mengaitkan data-data tersebut dengan teori. Hasil praktikum yang diperoleh dapat membantu peserta didik dalam menyelidiki atau membuktikan kebenaran suatu konsep materi, terutama konsep yang bersifat abstrak. Hal senada 
diungkapkan oleh peneliti terdahulu bahwa melalui praktikum virtual peserta didik dapat lebih mengeksplorasi konsep materi yang bersifat abstrak sehingga peserta didik mampu memecahkan masalah dari lembar kerja yang diberikan dan membantu dalam meningkatkan pemahaman konsep materi (22).

Serangkaian kegiatan praktikum yang dilakukan oleh peserta didik tidak terlepas dari sikap ilmiah peserta didik. Sikap ilmiah membantu jalannya proses pembelajaran yang lebih terstruktur sehingga ilmu yang diperoleh lebih terorganisir dan konseptual (23). Melalui kegiatan praktikum peserta didik diarahkan layaknya seorang peneliti sehingga dapat melatihkan sikap ilmiah peserta didik. Perlu dorongan yang kuat ke dalam diri peserta didik agar terbentuk sikap ilmiah yang diharapkan. Rasa ingin tahu, jujur, tanggung jawab, logis, berpikir kritis, analitis, dan kreatif adalah sikap ilmiah yang diamati selama kegiatan praktikum berlangsung. Dengan melatihkan sikap-sikap ilmiah tersebut diharapkan peserta didik dapat menyelesaikan berbagai pemecahan persoalan, baik persoalan di lingkungan belajar maupun dalam kehidupan sehari-hari, tanpa mengesampingkan sikap ilmiah.

Pemanfaatan laboratorium virtual di dalam kegiatan pembelajaran, khususnya kegiatan pembelajaran jarak jauh di masa pandemi Covid-19, tentunya mempunyai daya tarik bagi peserta didik. Ketika kegiatan pembelajaran yang hanya monoton terhadap pemberian tugas dan rangkuman materi, maka dengan adanya praktikum secara virtual memberikan warna baru di dalam kegiatan pembelajaran jarak jauh, seperti mengurangi kebosanan belajar peserta didik. Dengan begitu, peserta didik lebih mudah dalam menguasai konsep materi dan sikap ilmiah peserta didik berangsur-angsur tumbuh melalui pembelajaran dengan laboratorium virtual.

Senada dengan hasil penelitian terdahulu bahwa hasil rekapitulasi antara pretest dan posttest mengindikasikan adanya peningkatan skor rata-rata pemahaman konsep peserta didik yang sangat baik (24). Hal ini disebabkan karena peserta didik diberi rangsangan dengan hal-hal baru sehingga pikiran peserta didik menjadi aktif dan peserta didik menjadi lebih antusias dalam mengikuti pembelajaran. Begitu pula dengan hasil observasi sikap ilmiah peserta didik yang juga memperoleh persentase yang baik. Hasil penelitian ini mengisyaratkan bahwa pemahaman konseptual yang baik dapat diperoleh dari persentase sikap ilmiah yang baik pula. Namun secara umum penelitian yang telah peneliti lakukan tidak sama dengan peneliti sebelumnya. Penelitian yang telah peneliti lakukan berbeda dalam hal materi, tempat, dan jenjang pendidikan yang dipilih.

\section{SIMPULAN DAN SARAN}

\subsection{Simpulan}

Penelitian yang dilakukan di salah satu Madrasah Aliyah Prabumulih dengan sampel satu kelas $\mathrm{X}$ IPA telah peneliti lakukan sebaik mungkin agar dapat memberikan gambaran hubungan penguasaan konsep dan sikap ilmiah peserta didik dalam pembelajaran berbasis laboratorium virtual. Namun penelitian ini masih terdapat keterbatasan, diantaranya terbatasnya topik praktikum virtual yang dilakukan. Peneliti hanya dapat mengambil beberapa topik percobaan saja, seperti resultan gaya dan hukum I Newton, gerak benda pada bidang datar licin, gerak benda pada bidang datar kasar, gerak benda pada bidang miring licin, dan gerak benda pada bidang miring kasar. Hal ini disebabkan karena percobaan pada PhET interactive simulation yang tersedia masih terbatas, seperti pada percobaan/animasi penerapan hukum Newton pada lift belum ada. Selain itu, waktu penelitian yang dilakukan juga terbatas. Meskipun demikian, hasil pengolahan data, analisis dan pembahasan yang telah dilakukan mampu memberikan gambaran yang positif mengenai hubungan penguasaan konsep dan sikap ilmiah peserta didik dalam pembelajaran berbasis laboratorium virtual.

Hasil analisis uji korelasi dengan $n=28$ dan taraf signifikansi $(\alpha) 5 \%$ diperoleh $r_{\text {hitung }}>r_{\text {tabel }}$ $(0,589>0,374)$, yang artinya $H o$ ditolak dan $H a$ diterima. Hasil ini menunjukkan terdapat hubungan penguasaan konsep dan sikap ilmiah peserta didik dalam pembelajaran berbasis laboratorium virtual pada materi Dinamika Gerak. Tingkat korelasi antara penguasaan konsep dan sikap ilmiah dikategorikan sedang. Maka dengan jumlah sampel yang dipilih kiranya dapat mewakili karakteristik populasi secara keseluruhan. Sehingga secara umum dapat disimpulkan

Hubungan Penguasaan Konsep dan Sikap IImiah Peserta Didik dalam Pembelajaran Berbasis Laboratorium Virtual di Masa....

Indri Pratiwi, Sardianto Markos Siahaan, Syuhendri 
bahwa terdapat hubungan penguasaan konsep dan sikap ilmiah peserta didik dalam pembelajaran berbasis laboratorium virtual pada materi Dinamika Gerak dengan tingkat korelasi sedang.

\subsection{Saran}

Saran untuk penelitian selanjutnya yaitu diharapkan dapat meneliti dan mengkaji lebih mendalam mengenai penguasaan konsep Fisika dan sikap ilmiah peserta didik menggunakan laboratorium virtual dengan topik materi yang berbeda agar kedepannya diperoleh hasil penelitian yang lebih akurat.

\section{DAFTAR PUSTAKA}

1. Kamba AH, Giwa AA, Libata IA, Wakkala GT. The Relationship Between Science Process Skills and Student Attitude Toward Physics in Senior Secondary School in Aliero Metropolis. African Educ Res J. 2018;6(3):107-13.

2. Zulirfan, Iksan ZH, Osman K, Salehudin SNM. Take-Home-Experiment: Enhancing Students' Scientific Attitude. J Balt Sci Educ. 2018;17(5):828-37.

3. Syuhendri. The Development of Newtonian Mechanics Conceptual Change Texts to Overcome Students' Misconceptions. J Educ Learn. 2018;12(3):510-9.

4. Sania L, Syuhendri S, Akhsan H. Pengembangan Bahan Ajar Teks Perubahan Konseptual (TPK) Materi Fisika Dasar Topik Kinematika. J Kumparan Fis. 2021;4(1):43-50.

5. Virgana. Penguasaan Konsep Fisika, Penggunaan Media Musik, dan Gaya Belajar Siswa. J Ilmu Pendidik. 2018;23(1):53-59.

6. Maison, Ernawati MDW, Budiarti RS, Kurniawan W, Ningsih Y, Puspitasari TO, et al. Learning In Nature Science: Social Implications, Normality of Scientist, Attitudes Towards Investigation of Natural Science, and Interest Adds to Science Learning Time. Int J Sci Technol Res. 2019;8(12):1478-84.

7. Hakİm A, Liliasari, Kadarohman A, Syah YM. Effects of the Natural Product Mini Project Laboratory on the Students Conceptual Understanding. J Turkish Sci Educ. 2016;13(2):2736.

8. Zeidan AH, Jayosi MR. Science Process Skills and Attitudes toward Science among Palestinian Secondary School Students. World J Educ. 2015;5(1):13-24.

9. Thapliyal L, Sharma S, Godiyal S. ICT In Teaching: A Critical Overview. Indian J Appl Res. 2016;6(6):95-7.

10. Afzal MT, Safdar A, Ambreen M. Teachers Perceptions and Needs towards the Use of ELearning in Teaching of Physics at Secondary Level. Am J Educ Res. 2015;3(8):1045-1051.

11. Syuhendri. Integrasi TIK dan Pedagogi untuk Meningkatkan Daya Guna Teknologi dalam Dunia Pendidikan. In: Disampaikan dalam Seminar Nasional Pendidikan FKIP UNSRI 2009. 2009.

12. Topalsan AK. Development of Scientific Inquiry Skills of Science Teaching Through Argument-Focused Virtual Laboratory Applications. J Balt Sci Educ. 2020;19(4):628-46.

13. PhET-Team. PhET Interactive Simulation [Internet]. Diakses pada November 2020. 2020. Available from: https://phet.colorado.edu/

14. Syuhendri. A Learning Process Based on Conceptual Change Approach to Foster Conceptual Change in Newtonian Mechanics. J Balt Sci Educ. 2017;16(2):228-40.

15. Puspendik. Laporan Hasil Ujian Nasional [Internet]. Diakses pada November 2020. 2020. Available from: https://hasilun.puspendik.kemdikbud.go.id/ 
16. Shinta R, Khumaedi. Pengaruh Pembelajaran Berbasis Praktikum Terhadap Pengembangan Sikap Ilmiah Siswa Kelas XI IPA SMA Islam Sudirman Ambarawa. Unnes Phys Educ J. 2015;4(1):49-53.

17. Suana W. Pengembangan Perangkat Pembelajaran Listrik Dinamis Berbasis Virtual Experiment untuk Kuliah Teori dan Praktikum Terintegrasi. J Pendidik Fis Univ Muhammadiyah Metro. 2017;5(1):46-61.

18. Yunita, Halim A, Safitri R. Meningkatkan Penguasaan Konsep Mahasiswa dengan Simulasi Physics Education and Technology (PhET). J Pendidik Sains Indones (Indonesian J Sci Educ. 2019;07(01):16-22.

19. Sugiyono. Metode Penelitian Kuantitatif Kualitatif dan R\&D. Bandung: Alfabeta; 2012.

20. Hestenes D, Wells M, Swackhamer G. Force Concept Inventory. Phys Teach. 1992;30(3):141-158.

21. Tekbiyik A, Ercan O. Effects of the Physical Laboratory Versus the Virtual Laboratory in Teaching Simple Electric Circuits on Conceptual Achievement and Attitudes towards the Subject. Int J Progress Educ. 2015;11(3):77-89.

22. Prima EC, Putri AR, Rustaman N. Learning Solar System Using PhET Simulation to Improve Students' Understanding and Motivation. J Sci Learn. 2018;1(2):60-70.

23. Astalini, Darmaji, Pathoni H, Kurniawan W, Jufrida, Kurniawan DA, et al. Motivation and Attitude of Students on Physics Subject in the Middle School in Indonesia. Int Educ Stud. 2019;12(9):15-26.

24. Zahara S, Haji AG, Syukri M. Improving the Concept Understanding and Scientific Attitudes through the Implementation of Scientific Approach. Tadris J Kegur dan Ilmu Tarb. 2018;3(1):55-66. 